\title{
Application of Original Ecological Design in Architectural Space Innovation Design
}

\author{
Tao Shen, Yukari Nagai \\ Knowledge Science, Japan Advanced Institute of Science and Technology, Nomi City, Japan
}

Keywords: original ecology, architectural design, creative design, architectural space

\begin{abstract}
In this paper, we argue that the design of ecological architecture should take into consideration all kinds of architectural and environmental factors. In the construction, we should not only meet the requirements of the development of the ecological environment, but also meet the characteristics of people living. In order to integrate the environment in the process of architectural space design, it is necessary to take full account of the natural conditions and the ecological environment of the site of the building, and effectively integrate the ecological building technology into the architectural design, and finally put forward a design scheme with economic, social and environmental benefits.
\end{abstract}

\section{Introduction}

Ecological architecture is to apply the principles and methods of ecology to the architectural design, taking the coordinated development of human, natural environment, architecture and society as the research object, using natural resources to obtain the harmonious unity between human beings, human and environment, and creating an ecological environment for human survival and development [1].

The main contents of the ecological building include the following aspects: creating a healthy, comfortable, and unpolluted activity and living environment for the human beings; when the construction and construction of the ecological building, the natural conditions and natural resources should be maximally utilized, and the ecological environment should be protected on the basis of the ecological environment [2]. The utilization rate of resources will reduce the consumption of all kinds of non renewable energy in nature to the lowest; in the process of construction and construction, the recycling and recycling of resources should be advocated; the outer environment of the ecological building needs to be disposed of green space, and the landscape design should be combined to improve the landscape and maintain the construction of the community. Ecological balance in small ecosystems such as buildings or other buildings [3].

\section{The principles of the original ecological landscape design in $\mathbf{2}$ cities}

Plant landscape construction should be based on different geographical conditions, regional culture and green space. The plant landscape should achieve a scientific, artistic and cultural unity, which needs to be built on the basis of ecological principles, artistic principles and cultural principles [4].

\subsection{Ecological Principles}

Plant landscape plant allocation should follow the principles of ecology, select plant varieties rationally, and form a plant community with reasonable structure, stable population, mutual supplement and full utilization of resources [5]. Plant landscape ecology is not only the coordination and stability between plants and plants, but also between plants and humans. It enables people to feel the harmony and stability of nature in plant space. The introduction of landscape ecology has increased the landscape of plant plants to a higher level of maintaining the balance of human living space, protecting species diversity and reappearing nature.

The ecological principles of plant landscape construction include the following two aspects: (1) 
follow the natural conditions and the ecological habits of plants. The geographical conditions of each region have their own characteristics. The planted plants should conform to their geographical and climatic conditions. The garden plant landscape can not be imitated blindly, and the cost of plant cultivation which is not suitable for local growth is high, and the landscape effect can not reach the expected landscape effect. In the same geographical conditions, plants also have different physiological and ecological characteristics, such as joy, Yin, Yang, water and drought. According to its growth law, we should choose suitable location for planting. Follow the principle of proper trees. (2) abide by the principle of biodiversity. The plant community has few varieties, simple structure, easy to reverse succession, increase disease and reduce ecological benefits. We should make full use of native species and species richness to form abundant natural community landscapes. We should introduce new varieties reasonably, domesticate wild ornamental plants and enrich plant species. According to plant habits, we should build three-dimensional plant communities scientifically. Note the relationship between plant allelopathy of plant community harmonious construction. Follow the natural law from the community from the natural community composition, structure, nature to plant landscape configuration [4-5].

\subsection{Artistic Principles}

Garden plant landscape is a form of art formed by people in the practice of aesthetic practice. The main purpose is to meet the aesthetic needs of the people. It is presented in the form of art under the premise of satisfying the ecological effect and practical value. When we plant landscapes, we should respect the ecological habits of plants and construct them based on aesthetic principles. The artistic principles of plant landscape include the principle of form beauty, the principle of color beauty and the principle of space.

(1) the principle of formal beauty of plant landscape, and the structure form created by plants according to the law of beauty. This structure includes the relationship between the morphology, proportion, scale and unity of plant individual and plant community structure, and the symmetry and balance, rhythm and rhythm in the structure show a kind of order. The specific expression is to analyze the essence of the beauty of the plant and to explore the beauty of the plant morphology; the allocation of plants to the balance of posture, density, volume and comparative structure; the rich landscape level of plants, the organization of space and the three-dimensional level, the plant landscape as the carrier of dynamic beauty and the addition of the plant landscape in the three-dimensional space. Among the elements, the plant landscape making, wind rain and snow, sunny morning when four different seasonal landscape features.

(2) the color beauty principle of plant landscape, the different colors of the four seasons brought by the plant landscape, the spring flower brocade, the green tree shady, the autumn leaf like fire and the red dress are all the different aesthetic enjoyment to us. The construction of plant landscape should follow different attributes of color to create different psychological feelings of visitors. First of all, we should actively apply the color beauty of plants. Because of the color, color and color of different plants, we should make great efforts to explore all kinds of plant resources with beautiful colors. The color of garden landscape is more colorful. Then we should configure plant landscape in accordance with color color, brightness, purity three properties and color complement, cold and warm, area, hue and other relative relations to configure the plant community. On the basis of scientific community, we can achieve color change and unity. Finally, to take into account the color of plant landscape four changes, do four a king or a prominent seasonal landscape landscape effect. In addition, the common landscape of plant color in modern garden is particularly prominent in the theory of color composition. At the same time, it also requires that the color composition theory should follow the principle of color beauty.

(3) the spatial principle of plant landscape, the use of plant segmentation and enclosure space is an important role of plant landscape, the use of high and low density of plants to create open or closed space, to form different psychological feelings of people. Environmental psychology holds that human action and psychology are affected and changed by environmental space. Rational use of environmental psychology knowledge and plant materials to design plant landscapes to form 
plant spaces that meet people's different psychological needs, such as providing security, quiet space, quiet space, and open space for communication activities.

\subsection{Principles of Culture}

Plant landscape is the unity of external image and inner spiritual culture. The garden culture formed by plant landscape is also an important part of traditional culture in China. Landscape plants not only exist as the external beauty of the city, but also constitute the connotation and culture of the city spirit with architecture, diet and folk custom. The long garden landscape has witnessed the history of the city and the continuation of the urban context. Communication with foreign garden culture enables local garden culture and other cultures to be communicated to the outside world. Since eighteenth Century, Chinese garden culture has had an impact on the British garden culture. In the middle of the eighteenth Century, Chinese style was very popular in the British garden design. In nineteenth Century, the Royal Botanical Garden Qiu garden began to introduce a large number of plants in China. A large number of plants, such as the wall garden, the peony peony garden, the Maple Garden, the rock garden and so on, had come from China, and had an important influence on the art of British gardening.

(1) cultural principle requires the creation of artistic conception. Chinese classical gardens, as the fine works in Chinese art history, have unique cultural connotations. It has created the cultural achievement of using plants to create artistic conception. China's long culture endows plants with abstract and emotional aesthetic ideas. This poetic landscape can be lyrical and expressive. Create a scene of plant landscape beauty is the beauty of artistic conception. The beauty of artistic conception is the purpose of garden plant landscape, and the essence of Chinese landscape culture.

(2) cultural principles require the configuration of plant landscape to create a cultural atmosphere of a specific environment, and use different plant communities and historical sites, private courtyards, cemetery cemetery, religious temples, green squares and other different sites to form a corresponding cultural atmosphere. It enables people to feel sympathy in the environment of plant creation.

(3) the principle of culture requires the discovery of zonal plants and representative plant landscapes in a region or city. Highlight the city regional characteristics with the city tree and the city flower and the symbolic meaning of the plant, establish the city cultural image. Using some plants' personification spirit quality can represent the spirit of a city. Such as the faithful and unyielding of pine and cypress, the leisure and dissipation of bamboo, the elegance and elegance of plum blossoms, the cream of autumn chrysanthemums, the development of Magnolia. The use of zonal plants to create local landscape culture and regional customs, such as the coconut tree landscape is the representative of the tropical climate of Hainan, the pine and cypress landscape represents the scenery of the north.

(4) the cultural principle requires the protection and application of the plant landscape of ancient tree and name wood. The trees of more than one hundred years can be called ancient trees. The ancient trees with historical, scientific and social effects are called the famous trees. As a witness of cultural heritage in a region, ancient and famous trees play an immeasurable role in the cultural transmission and dissemination of a region. When building plant landscapes, we should protect and scientifically utilize ancient and famous tree resources and give play to their cultural significance.

\section{Integration of Ecological Architecture Design and Environment}

In the ecological architecture, we should embody the harmonious co-existence of man and nature. We should reflect the concern and respect for the natural environment and integrate with the surrounding environment.

Architecture, as a stable and intangible image, always needs the help of the surrounding environment and proper and harmonious layout to get the perfect performance. In the ecological architecture, giving the building green, means building can integrate with the nature. Green space (including public green space, green space beside the house or the green space between the house, green space of public service facilities and road green space four kinds), the roof greening and 
interspersed in the building floor, green space and so on. Reasonable three-dimensional greening (including green space, roof greening, environmental greening, etc.) has the role of protecting and stabilizing the regional ecological effects. The purpose of greening is to use the photosynthesis of plants to improve the conversion of carbon dioxide and oxygen in the surrounding area, to use the recycling system and to use the plant to intercept the dust, to kill bacteria, to reduce noise, to improve the climate and to beautify the environment, so as to receive the overall ecological benefits.

People's psychological needs become more and more important after their physiological needs are satisfied. The creation of the environment is to create a comfortable, healthy and beneficial space with natural hot spots inside and outside the building, especially in the public space, with artistic greening, water surface, seat and conversation. In the general layout design, try to avoid the inflexibility of external space, and strive to create a lively and lively outdoor space. Secondly, environmental design. We should consider more about interpersonal relationships, the need for neighborhood interaction, and set up necessary public places and contacts.

In architectural design, the building site must be fully considered, including the orientation, positioning, layout of the building, the use of terrain and terrain, the influence of the climate conditions of the site, etc. Make use of renewable energy, make use of renewable energy such as solar energy utilization, natural cold source, natural lighting, ventilation, and dehumidification, use local technology and materials to reduce construction costs as much as possible; consider the concern of the users, pursue efficient and economical, take account of human health and comfort, and make the building people suit. The purpose of building is comfort, nature and convenience.

In addition, we should strengthen the communication between the user and the natural environment, and introduce the natural elements to the user as much as possible, and make the building a bridge between the users and the natural environment, rather than the heavy barrier between the human and the natural environment, so as to ensure that people live and work in a strong and natural environment. It is healthier, more comfortable and more energetic.

\section{Creative Design Measures for Building Space}

It is the key to improve the comfort and health of the living environment to improve the comfort of the indoor environment and ensure a good indoor environment by adopting appropriate technology of insulation, heat insulation, air exchange, sound insulation and lighting. In the design of small and medium-sized dwelling houses, we should strive for better orientation and ventilation environment according to the climatic conditions in this area. Direct lighting should be made in the main rooms of the house. The living rooms and bedrooms should strive for one or two southern directions, especially for the living room with a certain area of windows, otherwise the light will be dim and inconvenient to use. The indoor sound environment mainly refers to the sound insulation effect of the sound insulation of the wall and the floor of the floor and the sound of floor impact. At present, the sound insulation technology of the floor impact sound is mainly solved, for example, the floating sound insulation layer can be used. Light environment mainly refers to the natural lighting value standard of a room, which is usually obtained through window opening. But the size of the room window needs to meet the ratio of the window and ground area, but it should be noticed that the window area is not as big as possible, and the conference brings the negative effects of large energy consumption, poor privacy and even insecurity. The thermal environment refers to the effect of heat preservation and insulation in the room. Different regions need to emphasize different priorities and take different measures to achieve the requirement of warm winter and cool summer. For general insulation, the comprehensive system of external thermal insulation should be applied. Thermal insulation needs wall insulation and window insulation, and the effective measure is external shading. The key of air quality environment is to ensure indoor air convection and form good ventilation. For the environmental quality of small and medium-sized apartments, it is necessary to adopt advanced science and technology, more important is to choose materials, to make full use of natural resources, to do a good job in planning and design, for example, to strive for sufficient sunshine, to organize unobstructed wind and flow, to cover the sun in the west, to be 
reasonable in shape coefficient, to the ratio of window to wall area, to the ratio of window to floor area, and so on, both economic and economic. And it has practical results.

This requires a variety of industry industries, including design, to work together, pay attention to standardization and industrialization, so that designers can choose a thinner wall to increase the use of more area, and can choose more equipment to better meet the requirements of energy saving, ventilation, lighting and so on. The coordination of the overall supporting measures and the increase of the proportion of small and medium sized businesses will inevitably increase the number of households, which in turn leads to changes in the supporting facilities. If the increase in the number of families will inevitably bring about the increase of children, the school matching in this area is bound to be modified, and the design of parking space must be increased, as well as commercial matching, the change of green rate and so on, these are very complex, the city planners need to re regulate and coordinate. At present, in some big cities, it is encouraged to reduce the height and volume rate, improve the building density, and promote the low level and individualized development of the residential buildings, and return to the friendly scale of the buildings and people: the continuity of the space from the high to the low, the density from the low to the high, and the kindly and agreeable of the residential buildings in the suburbs. The condition is provided. After the small and medium-sized apartments were increased, the household density increased, which directly involved in environmental problems, not because of the small and medium-sized apartments, the environment was bad. Small and medium-sized apartment in the environmental design is also innovative. We must do all good landscape in the planning, each household has a good face, good landscape. At the same time, due to homogenization of housing population, planning should also increase more communication between communities.

\section{Summary}

Small and medium-sized apartments also involve the problem of per capita living density and Huxing density. This problem is worth further studying. In a word, the small and medium type housing in residential buildings is a house which meets the wide demand of the society. The small and medium type housing should be a residential product that meets the utility, comfort, applicability, safety, environmental protection and economy at the same time.

\section{References}

[1] Yingdong H U, Shen B. Application of Virtual Reality Technology in Architectural Research and Design-Case Study of Transitional Space of Traffic Hubs[J]. Building Science, 2017.

[2] Guo R, Yang L X, Hou Y, et al. On Application of Virtual Reality Technology to Landscape Designing[J]. Journal of Shenyang Agricultural University, 2009.

[3] Zhu H. Shallow Talk about Virtual Reality Technology and Its Application in Mechanical Design and Manufacturing[J]. Science \& Technology \& Innovation, 2015.

[4] Zhang S N, Niu Y. The Application of Virtual Reality 3D User Interface Technology to Industrial Design[J]. Development \& Innovation of Machinery \& Electrical Products, 2011.

[5] Campbell Z, Zakzanis K K, Jovanovski D, et al. Utilizing virtual reality to improve the ecological validity of clinical neuropsychology: an FMRI case study elucidating the neural basis of planning by comparing the Tower of London with a three-dimensional navigation task.[J]. Applied Neuropsychology, 2009, 16(4):295-306. 